$$
\text { Pontifícia Universidade C Católica }
$$

Pedro Paulo Alves dos Santos

Exegese bíblica em diálogo com estudos literários

Tese de Doutorado

Tese apresentada ao Programa de Pós-graduação em Letras do Departamento de Letras da PUC/Rio como parte dos requisitos parciais para obtenção do título de Doutor em Letras.

Orientadora: Profa. Heidrun Friedel Krieger Olinto de Oliveira

Rio de Janeiro

Abril de 2006 


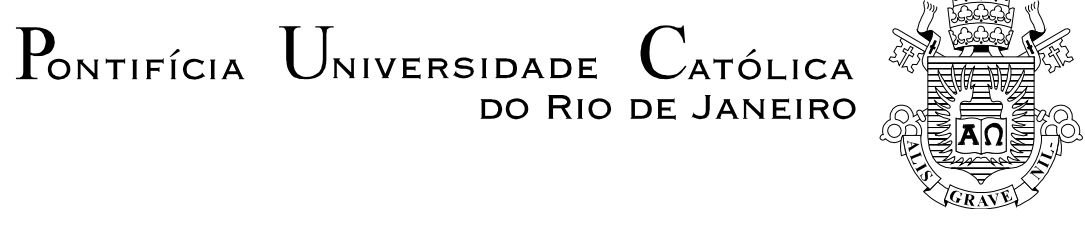

Pedro Paulo Alves dos Santos

\section{Exegese bíblica em diálogo com estudos literários}

Tese apresentada como requisito parcial para obtenção do grau de Doutor pelo programa de Pós-Graduação em Letras do Departamento de Letras do Centro de Teologia e Ciências Humanas da PUC-Rio. Aprovada pela Comissão Examinadora abaixo assinada.

Profa. Heidrun Friedel Krieger Olinto de Oliveira Orientadora Departamento de Letras - PUC-Rio

Profa. Eliana Lúcia Madureira Yunes Garcia Departamento de Letras - PUC-Rio

Profa. Maria Clara Lucchetti Bingemer Departamento de Teologia - PUC-Rio

Profa. Daniela Gianna Claudia Beccaccia Versiani UNESA

Prof. José Carlos Barcellos Instituto de Letras - UFF
Prof. Paulo Fernando Carneiro de Andrade
Coordenador Setorial do Centro de Teologia e Ciências Humanas - PUC-Rio

Rio de Janeiro, de de 
Todos os direitos reservados. É proibida a reprodução total ou parcial do trabalho sem autorização da universidade, do autor e da orientadora.

\section{Pedro Paulo Alves dos Santos}

Concluiu o doutorado em Teologia Bíblica - Pontificia Università Gregoriana Di Roma em 1997 e em Letras, pela Pontifícia Universidade Católica do Rio de Janeiro, em 2006. Atualmente é membro da Faculdade de Letras da Unesa e do Ccaa. Desde de 2002 é o Editor-Responsável pela COMMUNIO. Revista Internacional de Teologia e Cultura. Publicou 16 artigos em periódicos especializados e 4 trabalhos em anais de eventos. Possui 4 capítulos de livros. Atua na área de Teologia, com ênfase em Exegese Neotestamentária. Os termos mais freqüentes na contextualização da produção científica, tecnológica e artístico-cultural são: Estudos de Literatura, Exegese e Hermenêutica. História antiga e medieval.

Ficha Catalográfica

Santos, Pedro Paulo Alves dos

Exegese bíblica em diálogo com estudos literários / Pedro Paulo Alves dos Santos ; orientadora: Heidrun Friedel Krieger Olinto de Oliveira. - Rio de Janeiro : PUC, Departamento de Letras, 2006.

$239 \mathrm{f} . ; 30 \mathrm{~cm}$

Tese (doutorado) - Pontifícia Universidade Católica do Rio de Janeiro, Departamento de Letras.

Inclui referências bibliográficas.

1. Letras - Teses. 2. Estudos literários. 3. Leitura. 4. Exegese bíblica. I. de Oliveira, Heidrun Friedel Krieger Olinto. II. Pontifícia Universidade Católica do Rio de Janeiro. Departamento de Letras. III. Título. 
Aos meus queridos Pais, Antonio Paulo e Maria Madalena, meus irmãos, Jorge, Elvira, Isabel, Lourdes, meus sobrinhos, que têm estado carinhosamente ao meu lado por tantos anos, compartilhando dos momentos mais importantes de minha vida.

In Memoriam de Savério Maturo, pela amizade e carinho que se perpetua na vida de sua esposa Zara Magalhães Maturo.

A Floremy Roldão pelo que me ensinou sem perceber. 


\section{Agradecimentos}

À minha orientadora e grande amiga, Professora HEIDRUN KRIEGER FIEDLER OLINTO, pelos ensinamentos e presença marcante ao meu lado por tantos anos, participando de minha trajetória acadêmica. Sua orientação e incentivos e, sobretudo sua paciência foram muito indispensáveis para a conclusão desta tese.

À Professora Doutora, PROFA. ELIANA LÚCIA MADUREIRA YUNES GARCIA que, com sua insuperável competência profissional, além da sempre amabilidade e receptividade, me apresentou o mundo da leitura e da mística literária.

À Professora Doutora PROFA. MARIA CLARA LUCCHETTI BINGEMER, Decana do CTCH, Teóloga do Diálogo, agradecido pela sua participação em minha Banca, pelo respeito às diferenças.

Aos Professores Doutores .DANIELA GIANNA CLAUDIA BECCACCIA VERSIANI e. JOSÉ CARLOS BARCELLOS, ilustres membros da Banca, pela generosa e competente leitura de minha Tese e pela contribuição no seu aperfeiçoamento.

Ao Professor e amigo, Reinaldo Kelmer, pelos diálogos e pela estimulante parceria..

Ao Programa de Pós-Graduação do Departamento de Letras da Pontifícia Universidade Católica, que me acolheu, tão generosamente e sempre respeitou minha condição de ‘estrangeiro’ em seu habitat.

Ao apoio financeiro da CAPES, sem o qual não teria sido possível concluir este percurso acadêmico.

À CHIQUINHA, Secretária da Pós-graduação do Departamento de Letras da PUC-Rio, pelo apoio, orientação burocrática e paciência em momentos de que mais precisei.

A Sra. Marcia Guerra pela indispensável disponibilidade na conclusão deste percurso. 


\section{Resumo}

dos Santos, Pedro Paulo Alves; de Oliveira; Heidrun Friedel Krieger Olinto (Orientadora). Exegese bíblica em diálogo com estudos literários. Rio de Janeiro, 2006. 239p. Tese de Doutorado - Departamento de Letras, Pontifícia Universidade Católica do Rio de Janeiro.

A tese Exegese bíblica em diálogo com estudos literários apresenta uma nova perspectiva sobre os estudos exegéticos de textos bíblicos a partir de pressupostos teóricos atuais nos estudos de literatura. O acento é colocado sobre questões investigadas pela Estética da Recepção e do Efeito, objetivando a elaboração de categorias novas para o entendimento de processos de leitura. A tese visa, ainda, à formulação de uma historiografia do ato interpretativo "cristão", em função de premissas desenvolvidas para a leitura e a construção de sentido de textos literários, transpostas para o campo disciplinar exegético, hoje igualmente aberto ao diálogo e ao questionamento de interpretações fundadas em pressupostos essencialistas. Neste sentido, novas posturas hermenêutico-literárias, levando-se, em consideração, a historicidade de atos interpretativos, são articuladas com o entendimento e a configuração da exegese bíblica, como fenômeno literário “cristão" e como gênero "meta-textual”. As premissas heurísticas desenvolvidas por Wolfgang Iser, em vista de uma antropologia literária, oferecendo ao imaginário e aos processos interpretativos novas formas de produção de sentido em particular na apreciação da obra hermenêutica de Santo Agostinho e no discurso hermenêutico antigo e medieval - representam neste projeto as diretrizes epistemológicas, teóricas e estéticas centrais.

\section{Palavras-chave}

Estudos Literários, Leitura, Exegese Bíblica. 


\section{Abstract}

dos Santos, Pedro Paulo Alves; de Oliveira; Heidrun Friedel Krieger Olinto (Advisor). The Biblical Exegesis in dialogue with the Literary Studies. Rio de Janeiro, 2006. 239p. Ph.D. Thesis - Departamento de Letras, Pontifícia Universidade Católica do Rio de Janeiro.

The thesis The Biblical Exegesis in dialogue with the Literary Studies presents a new perspective over the exegesis studies of biblical texts from actual theoretical presuppositions of the literary studies. The differential aspect comes from questions under research by the Aesthetics of Reception and Effect, which aim the elaboration of new categories for the understanding of the reading processes. The study also aims at formulating a historiography of the "Christian" interpretative act along with premises developed for reading and understanding of literary texts, which are transposed to the exegesis field. Since this latter has been equally open to dialogue and questioning of interpretations based in essentialist presuppositions. In such a sense, considering the history of the interpretative acts, new hermeneutical-literary approaches are articulated with the understanding and the biblical exegesis configuration as a "Christian" literary phenomenon and as a “meta-textual” genre. The heuristic premises developed by Wolfgang Iser, which offer new ways of meaning production to the imaginary and the interpretative processes - particularly in the appreciation of the hermeneutic work of St. Augustine and in the ancient and medieval hermeneutic discourse — towards a literary anthropology represent the epistemological, theoretical and aesthetical guidelines of this project.

\section{Keywords}

Literary Studies, Reading Processes, Biblical Exegese. 


\section{Sumário}

1. Apresentação 9

2. Mudanças Paradigmáticas nos Estudos de literatura 15

2.1. Discurso Literário e novos Discursos historiográficos 22

2.2. Histórias de Literatura Hoje 38

2.3. Conceitos-Chave da teoria de W. Iser 52

2.4. O Imaginário Literário de Iser $\quad 59$

2.4.1. Estrutura, Função e Comunicação 60

3. O Magistério Contemporâneo e a Hermenêutica Bíblica 69

3.1. Introdução $\quad 69$

3.2. Breve Percurso Histórica da Hermenêutica Bíblica 74

3.2.1. A Hermenêutica Bíblica Judaica 76

3.2.2. A Tradução dos LXX ou Septuaginta 78

$\begin{array}{ll}\text { 3.2.3. A Hermenêutica Moderna } & 79\end{array}$

3.3. A Teoria do Texto de Paul Ricoeur 86

3.4. A teoria hermenêutica de Luigi Pareyson 95

$\begin{array}{lr}\text { 3.5. Conclusão } & 100\end{array}$

3.6. W. Iser na Atualidade da Exegese Bíblica 108

3.7. As Questões do Cristianismo a partir da crítica literária do Cânon do Novo $\begin{array}{ll}\text { Testamento } & 123\end{array}$

4. A Exegese em Diálogo com Teorias da Interpretação de Textos Antigos e Medievais

4.1. O Imaginário Medieval: Ficção e História 156

4.2. A concepção do Livro Cristão 170

5. A tradição de Leitura em Santo Agostinho 173

$\begin{array}{ll}\text { 6. Conclusão } & 211\end{array}$

$\begin{array}{ll}\text { 7. Referências bibliográficas } & 219\end{array}$ 